\title{
Outbreak
}

\section{Long term effect of infection control practices and associated factors during a major Clostridium difficile outbreak in Costa Rica}

\author{
Roy A Wong-McClure ${ }^{1}$, Elenita Ramírez-Salas ${ }^{1}$, Nury Mora-Brenes ${ }^{2}$, Lorena Aguero-Sandí ${ }^{1}$, Maritza \\ Morera-Sigler ${ }^{1}$, Xiomara Badilla-Vargas ${ }^{1}$, Marcela Hernández-de Merzerville ${ }^{3}$, Michele O'Shea ${ }^{4}$, \\ Elizabeth Bryce ${ }^{5}$ \\ ${ }^{1}$ Epidemiology Office and Surveillance, Caja Costarricense de Seguro Social, Genaro Valverde Building, Second \\ Avenue, San José, Costa Rica \\ ${ }^{2}$ Hospital San Juan de Dios, Caja Costarricense de Seguro Social, San José, Costa Rica \\ ${ }^{3}$ Hospital Nacional de Niños Dr. Carlos Sáenz Herrera, Caja Costarricense de Seguro Social, San José, Costa \\ Rica \\ ${ }^{4}$ University of Arizona College of Medicine, Phoenix, Arizona, United States \\ ${ }^{5}$ Vancouver General Hospital, Vancouver, British Columbia, Canada
}

\begin{abstract}
Introduction: The $C$. difficile BI/NAP 1 hyper virulent strain has been responsible for the nosocomial outbreaks in several countries. The present study describes the infection control strategies utilized to achieve outbreak control as well as the factors associated with a $C$. difficile BI/NAP 1 hyper virulent strain outbreak in Costa Rica.

Methodology: A descriptive analysis of the C. difficile outbreak was completed for the period of January 2007 to December 2010 in one affected hospital. An unmatched case-control study was subsequently performed to evaluate the association of exposure factors with $C$. difficile infection.

Results: The pattern of the outbreak was characterized by a sharp increase in the incidence rate during the initial weeks of the outbreak, which was followed by a reduction in the incidence curve as several infection control measures were implemented.

The $C$. difficile BI/NAP1 infection was associated with the prescription of antibiotics, in particular levofloxacin (OR: 9.3; 95\%CI: 2.1-40.2), meropenem (OR: 4.9, 95\%CI: 1.0-22.9), cefotaxime (OR: 4.3,95\%CI: 2.4-7.7), as well as a medical history of diabetes mellitus (OR: 2.9 , 95\% CI: 1.5-5.8).

Conclusions: The infection control strategies implemented proved to be effective in achieving outbreak control and in maintaining the baseline $C$. difficile incidence rate following it. The reported C. difficile outbreak was associated with the prescription of broad-spectrum antibiotics and a medical history of diabetes.
\end{abstract}

Key words: Clostridium difficile; enterocolitis; infection control; infectious disease outbreaks

J Infect Dev Ctries 2013; 7(12):914-921. doi:10.3855/jidc.2854

(Received 09 July 2012 - Accepted 07 February 2013)

Copyright $(C 2013$ Wong-McClure et al. This is an open-access article distributed under the Creative Commons Attribution License, which permits unrestricted use, distribution, and reproduction in any medium, provided the original work is properly cited.

\section{Introduction}

Clostridium difficile has been a reemerging nosocomial agent in diarrheal outbreaks. Risk factors for infection include: a) individual factors such as antimicrobial use, the use of proton pump inhibitors, advanced age and pre-existing disease; b) environmental factors such as inadequate disinfection and cross-contamination of medical equipment and supplies; and c) inadequate hand hygiene [1,5].

In recent years, a new strain, $C$. difficile BI/NAP1, has been characterized with an increased severity and higher mortality rate and a tendency to be present in developed countries [6,9].
Few $C$. difficile infections had been previously described in Latin America and have been restricted to cases within intensive care units [10]. More recently, there has been an important documented outbreak in Chile [11]. The Costa Rican outbreak was previously documented [12], however the risk factors associated, as well as the long term impact of the interventions for the control of $C$. difficile infection during the subsequent months, has been addressed by our outbreak study, with the confirmed existence of the B1/NAP1 type in this setting [13].

The present study is one of the first documented outbreaks in Latin America caused by the C. difficile 
BI/NAP1 strain, in which molecular typing has demonstrated the typical macrorestriction pattern of the NAP1 strain in $54 \%$ of the isolates, all of which the bacteria contained the gene for the binding domain of the binary toxin and a deletion in the $t c d C$ gene. From the rest of the isolates 4 stains were not toxin producers [14].

Between January and July 2009 a severe $C$. difficile BI/NAP1 outbreak was reported a Costa Rican General hospital, which was initially restricted to the medical wards and emergency department. Twelve weeks following the onset of the outbreak, the surgical wards were also affected.

The objective of this investigation was to determine the impact of a $C$. difficile infection on the control practices implemented, in order to achieve and maintain outbreak control for fifteen months following resolution of the initial outbreak, as well as determining factors associated with the $C$. difficile BI/NAP1 outbreak.

\section{Methodology}

The affected Costa Rican hospital is a 685-bed tertiary care centre providing specialized care to a population of around 900,000 people. Services include: medical, surgical, gynecological and obstetric care, which comprise a total of 31,000 yearly admissions.

\section{Study design}

A descriptive cross-sectional analysis of the $C$. difficile outbreak was completed from January 2007 to December 2010 in the affected hospital, by calculation of the incidence rate before and after the implementation of control measures. A case-control study was subsequently performed to test the hypothesis of antibiotic use and the outbreak, using all patients admitted between January and July of 2009 without prior hospital admissions as a case definition, with symptoms of acute diarrhea 48 hours after admission of hospitalization or 72 hours after discharge, with a positive culture-confirmed $C$. difficile toxin test controls were defined as all patients admitted to the hospital during the same time period had a negative $C$. difficile toxin test and without symptoms of diarrheal disease. Exclusion criteria were patients with diarrheal disease as the reason for admission as well as patients with previously documented $C$. difficile infection to avoid the inclusion of community-acquired cases.

\section{Laboratory analysis}

An enzymatic immunoassay detection kit for $C$. difficile toxin A B (Oxoid Ltd, Basingstoke, UK) was used for preliminary identification of disease in fresh fecal specimens. Toxin-positive isolates samples were further tested in thirty six samples by anaerobic cultivation. Isolates were recovered by placing inoculating loops of stool samples onto cefoxitincycloserine fructose agar plates (Oxoid, Ltd Basingstoke, UK), and were subsequently identified by the rapid ID32A system (BioMérieux, Marcy l'Etoile, FR) and PCR amplification of the triose phosphate isomerase gene. Isolates were typed by pulsed-field gel electrophoresis (PFGE) fragments of $t c d A, t c d B, c d t B$, and $t c d C$ genes were amplified by PCR with oligonucleotides [14].

\section{Sample size, case and control selection}

Sample size was calculated using the formula for case control studies [15] with 1.9 as a minimum Odds Ratio (OR) to be detected as significant, $53.0 \%$ of estimated antibiotic exposure rate in the control group, with a $95.0 \%$ significance level and $80.0 \%$ power. Random selection of cases and controls was performed with the random records selection function of Stata 10.1. Three control subjects were selected for each case to improve the OR estimation accuracy.

Cases were selected from a nosocomial surveillance information system in which infection control personnel routinely register affected patients' information in several hospital wards. Controls were selected from patient hospitalization records from the appropriate hospitalization period with the exclusion of records from the maternity, neonatology, and shortstay surgery services (Figure 1).

\section{Data management}

Data collected from the surveillance information systems were used in addition to information from a previously validated and standardized investigation form that was completed by epidemiology and infection control personnel. The form collected information on exposures of interest, which included medical history, length of hospitalization, and treatments prescribed and administered within a window of three weeks from the onset of symptoms for the cases to the discharge date. 
Figure 1: The flow chart of the selection of cases and controls show that the cases were selected randomly from 389 detected cases and the controls were selected randomly from 7,997 hospitalized patients without $C$. difficile infection. The exposures in cases and controls were evaluated after the selection process.

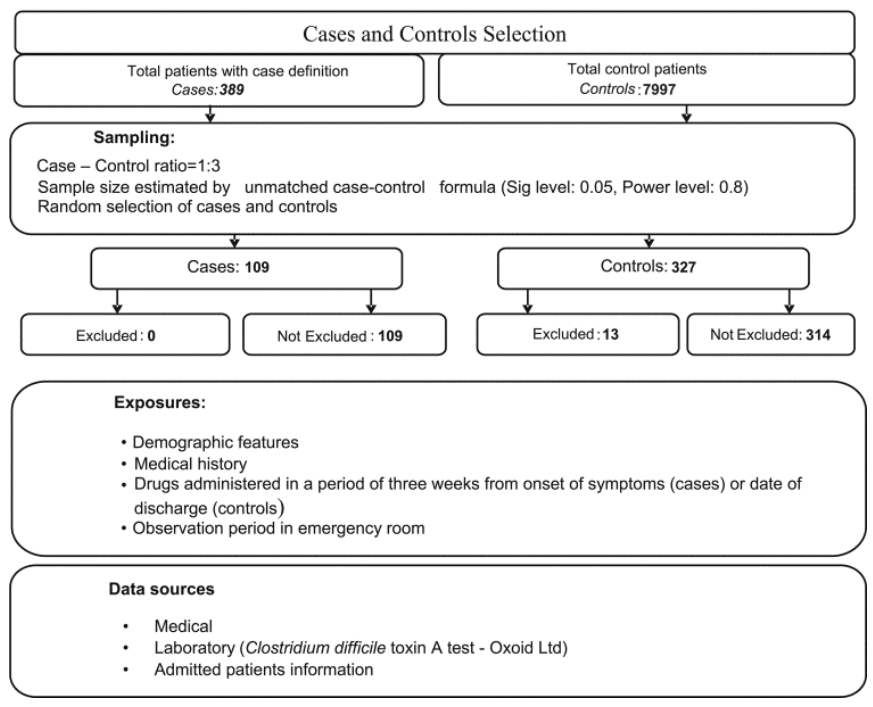

A large number of hospitalized patients underwent an observation period in the emergency department prior to admission, which was one of the initially affected services; therefore subjection to an observation period in the emergency department was considered to be an exposure.

\section{Data analysis}

A general description of the outbreak was performed based on the estimation of monthly incidence rates with the inclusion of implementation of control measures in the trend line.

For the case-control studies, the description and comparison of features of cases and controls were made with the chi square test $\left(\chi^{2}\right)$ for categorical variables.

Association of different factors with $C$. difficile infection was evaluated with 2 by 2 tables with adjusted estimates using a logistic regression model. A backward stepwise regression model was used which began with variables that demonstrated a Chi-square $\mathrm{p}$ value test less than 0.20 in the 2 by 2 tables evaluation and the inclusion of age and sex as confounders. Successive logistic models were calculated and significance was held at $\mathrm{p} \leq 0.05$.
Figure 2: The $C$. difficile baseline in the affected General Hospital in Costa Rica, increased dramatically from January 2009 to June 2009. Several infection control actions were applied and the more effective strategies to reach the outbreak control and keep the baseline were the enforcement infection control measurements and the restricted use of broad-spectrum antibiotics.

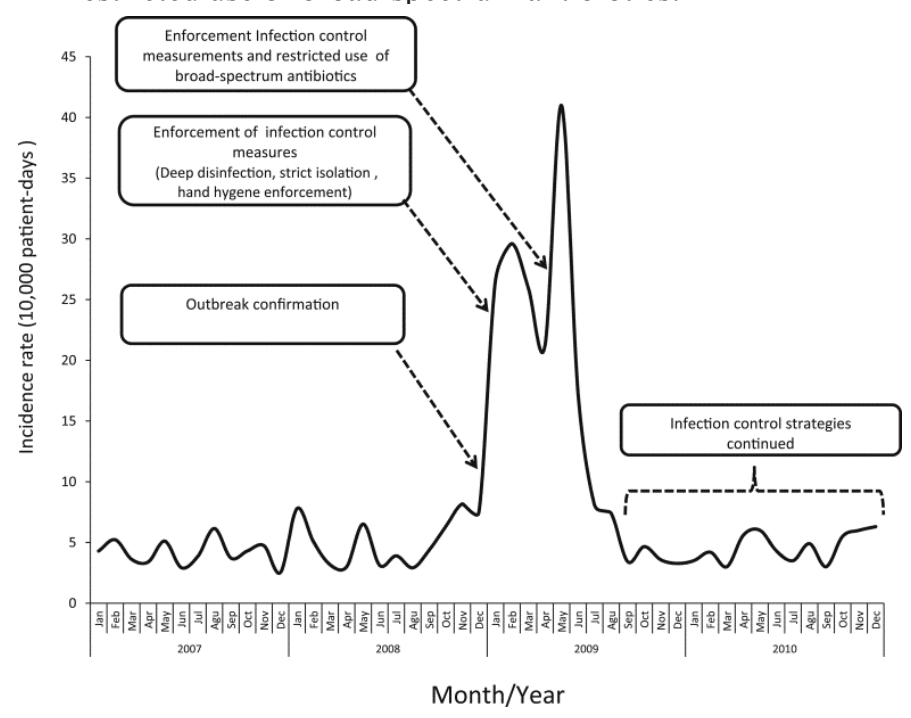

All analyses were performed with Stata 10.1 (Stata Corp, Texas USA 2009) and Epi Info 3.5.3 (CDC, Georgia USA 2011) for the chi-square test for trend.

\section{Results}

\section{General overview of the outbreak}

During the outbreak period, defined between January and July 2009, 389 cases were identified from the medical, emergency, and surgical wards, with isolates positive for both $t c d A$ and $t c d B$ [14]. Confirmation of the outbreak was declared during the third week of January, and the initial action implemented was the enforcement of general infection control measures. This included thorough cleaning and disinfection of affected wards with 1:10 hypochlorite solution and of medical equipment with 1:10 quaternary ammonium. Two monitored terminal room cleaning, based on the chlorine-containing agents, as recommended in the $C$. difficile guidelines of the Society for Healthcare Epidemiology of America (SHEA) and the Infectious Diseases Society of America (IDSA) [16], were successively applied in each cleaning session, with 45 minutes between the first and the second disinfection, a recommended method for the complete elimination of $C$. difficile spores [17]. 
Table 1: General features of cases and controls. Costa Rica General Hospital, January-July, 2009

\begin{tabular}{|c|c|c|c|c|c|}
\hline & & \multicolumn{2}{|c|}{$\begin{array}{l}\text { Controls } \\
(\mathrm{n}=314)\end{array}$} & \multicolumn{2}{|c|}{$\begin{array}{c}\text { Cases } \\
(\mathrm{n}=109) \\
\end{array}$} \\
\hline & & $\mathrm{n}$ & $\%$ & $\mathrm{n}$ & $\%$ \\
\hline \multirow[t]{2}{*}{ Sex } & Male & 161 & 51.3 & 58 & 53.2 \\
\hline & Female & 153 & 48.7 & 51 & 46.8 \\
\hline \multirow[t]{2}{*}{ Age group } & $<65$ years & 180 & 57.3 & 48 & 44.0 \\
\hline & $\geq 65$ years & 134 & 42.7 & 61 & 56.0 \\
\hline \multirow{2}{*}{$\begin{array}{l}\text { Emergency service } \\
\text { observation period }\end{array}$} & No & 109 & 34.7 & 13 & 11.9 \\
\hline & Yes & 205 & 65.3 & 96 & 88.1 \\
\hline \multirow{5}{*}{ Medical history } & Cancer & 39 & 12.4 & 7 & 6.4 \\
\hline & Diabetes mellitus & 35 & 11.2 & 37 & 33.9 \\
\hline & HIV/AIDS & 3 & 0.9 & 0 & 0.0 \\
\hline & Ulcerative colitis & 0 & 0.0 & 1 & 0.9 \\
\hline & End stage renal disease & 1 & 0.3 & 1 & 0.9 \\
\hline \multirow[t]{5}{*}{ Cephalosporins } & Cefotaxime & 58 & 18.5 & 68 & 62.4 \\
\hline & Cefalotin & 82 & 26.1 & 4 & 3.7 \\
\hline & Ceftazidime & 4 & 1.3 & 1 & 0.92 \\
\hline & Cefalexin & 11 & 3.5 & 1 & 0.9 \\
\hline & Ceftriaxone & 0 & 0.0 & 0 & 0.0 \\
\hline \multirow[t]{3}{*}{ Quinolones } & Ciprofloxacin & 30 & 9.6 & 34 & 31.2 \\
\hline & Levofloxacin & 3 & 0.9 & 10 & 9.2 \\
\hline & Ceftriaxone & 0 & 0 & 0 & 0 \\
\hline Sulfonamide derivatives & Sulfamethoxazole & 10 & 3.2 & 4 & 3.7 \\
\hline Tetracycline derivatives & Doxycycline & 8 & 2.6 & 1 & 0.9 \\
\hline \multirow[t]{4}{*}{ Penicillins } & Penicillin & 5 & 1.6 & 2 & 1.8 \\
\hline & Amoxicillin & 1 & 0.3 & 1 & 0.9 \\
\hline & Ampicillin & 8 & 2.6 & 1 & 0.9 \\
\hline & Oxacillin & 21 & 6.7 & 9 & 8.3 \\
\hline Oxazolidinione derivates & Linezolid & 0 & 0.0 & 1 & 0.92 \\
\hline \multirow[t]{3}{*}{ Aminoglycosides } & Gentamicin & 34 & 10.8 & 19 & 17.4 \\
\hline & Amikacin & 8 & 2.6 & 8 & 7.3 \\
\hline & Neomycin & 2 & 0.6 & 0 & 0.0 \\
\hline Macrolides & Clarithromycin & 13 & 4.1 & 18 & 16.5 \\
\hline Carbapenems & Meropenem & 3 & 0.9 & 12 & 11.0 \\
\hline $\begin{array}{l}\text { Gastric acid secretion } \\
\text { inhibitors }\end{array}$ & Proton-pump inhibitors * & 42 & 38.5 & 47 & 14.5 \\
\hline
\end{tabular}


Table 2: Evaluation of conditions associated with C.difficile infection. Costa Rica General Hospital, January-July, 2009

\begin{tabular}{|c|c|c|c|c|c|c|c|}
\hline Variable & & $\begin{array}{c}\text { Unadjusted } \\
\text { OR }\end{array}$ & CI 95\% & $\mathrm{P}$ & $\begin{array}{c}\text { Adjusted } \\
\text { OR }\end{array}$ & CI 95\% & $\mathrm{p}$ \\
\hline \multirow[t]{2}{*}{ Sex } & Male & 1.1 & $0.7-1.7$ & 0.7 & 1.0 & $0.6-1.7$ & 0.99 \\
\hline & Female & 1.0 & & & 1.0 & & \\
\hline \multirow[t]{2}{*}{ Age } & $<65$ years & 1.0 & & & 1.0 & & \\
\hline & $\geq 65$ years & 1.7 & $1.1-2.7$ & 0.02 & 1.2 & $0.7-2.1$ & 0.56 \\
\hline \multirow{2}{*}{$\begin{array}{l}\text { Length of } \\
\text { hospitalization }\end{array}$} & $<7$ days & 1.0 & & & 1.0 & & \\
\hline & $\geq 7$ days & 1.7 & $1.1-2.7$ & 0.02 & 1.6 & $0.9-2.9$ & 0.13 \\
\hline \multirow[t]{2}{*}{$\begin{array}{l}\text { Emergency } \\
\text { service } \\
\text { observation }\end{array}$} & No & 1.0 & & & 1.0 & & \\
\hline & Yes & 3.9 & $2.1-7.9$ & $<0.01$ & 1.4 & $0.7-3.0$ & 0.37 \\
\hline \multirow{5}{*}{$\begin{array}{l}\text { Medical } \\
\text { background }\end{array}$} & Cancer & 0.5 & $0.2-1.1$ & 0.08 & & & \\
\hline & Diabetes mellitus & 4.1 & $2.3-7.2$ & $<0.01$ & 2.9 & $1.5-5.8$ & $<0.001$ \\
\hline & HIV/AIDS & $\mathrm{NC}$ & & & & & \\
\hline & Ulcerative coltis & $\mathrm{NC}$ & & & & & \\
\hline & End Stage renal disease & 2.9 & $0.04-228.2$ & 0.43 & & & \\
\hline \multirow[t]{5}{*}{ Cephalosporins } & Cefalotin & 0.1 & $0.2-0.3$ & $<0.01$ & & & \\
\hline & Cefalexin & & & & & & \\
\hline & Cefotaxime & 7.3 & $4.4-12.2$ & $<0.01$ & 4.3 & $2.4-7.7$ & $<0.001$ \\
\hline & Ceftazidime & 0.7 & $0.0-7.4$ & 0.77 & & & \\
\hline & Ceftriaxone & $\mathrm{NC}$ & & & & & \\
\hline \multirow[t]{2}{*}{ Quinolones } & Levofloxacin & 10.5 & $2.6-59.9$ & $<0.01$ & 9.3 & $2.1-40.2$ & 0.003 \\
\hline & Ciprofloxacin & 4.3 & $2.4-7.7$ & $<0.01$ & 2.0 & $1.0-3.9$ & 0.04 \\
\hline $\begin{array}{l}\text { Sulfonamide } \\
\text { Derivatives }\end{array}$ & Sulfamethoxazole & 1.2 & $0.2-4.1$ & 0.81 & & & \\
\hline $\begin{array}{l}\text { Tetracycline } \\
\text { derivatives }\end{array}$ & Doxycycline & 0.4 & $0.0-2.7$ & 0.31 & & & \\
\hline \multirow[t]{4}{*}{ Penicillins } & Penicillin & 1.1 & $0.1-7.2$ & 0.86 & & & \\
\hline & Amoxicillin & 2.8 & $0.0-228.2$ & 0.43 & & & \\
\hline & Oxacillin & 1.2 & $0.5-3.0$ & 0.58 & & & \\
\hline & Ampicilin & 0.3 & $0.0-2.7$ & 0.30 & & & \\
\hline $\begin{array}{l}\text { Oxazolidinone } \\
\text { derivative }\end{array}$ & Linezolid & $\mathrm{NC}$ & & & & & \\
\hline \multirow[t]{3}{*}{ Aminoglycosides } & Gentamicin & 1.7 & $0.9-3.3$ & 0.07 & & & \\
\hline & Amikacin & 3.1 & $1.0-9.5$ & 0.02 & 0.5 & $0.1-2.0$ & 0.33 \\
\hline & Neomycin & $\mathrm{NC}$ & & & & & \\
\hline Macrolides & Clarithromycin & 4.6 & $2.0-10.5$ & $<0.01$ & 2.8 & $1.2-6.9$ & 0.02 \\
\hline $\begin{array}{l}\text { Gastric acid } \\
\text { secretion } \\
\text { inhibitors }\end{array}$ & Proton-pump inhibitors * & 3.6 & $2.1-6.0$ & $<0.01$ & 1.8 & $0.9-3.3$ & 0.08 \\
\hline Carbapenem & Meropenem & 12.8 & $3.3-71.7$ & $<0.01$ & 4.9 & $1.0-22.9$ & 0.04 \\
\hline
\end{tabular}


Contact isolation was enforced for suspected cases with mandatory use of single-use personal protective equipment, and a designated strict isolation area was established for confirmed cases. A hand hygiene enforcement campaign oriented towards both health care personnel and patients was also implemented.

Additional strategies directed towards medical staff and visitors were applied three weeks after the initial confirmation of the outbreak. This included measures such as the use of single-use personal protective equipment for each infected patient. These strategies significantly reduced the incidence rate from 29.6 cases/10 000 patient-days to 21.2 cases/10 000 patient-days in eight weeks $(\mathrm{p}=0.001)$.

During the final week of April the surgical wards began to report cases of $C$. difficile, while the overall incidence reached a rate of 40.9 cases/10 000 patientdays, an eight-fold increase in the usual incidence rate of nosocomial diarrheal infections (5 cases/10 000 patient-days) $(p=0.001)$. As a response, use of broadspectrum antibiotics (third-generation cephalosporins, fluoroquinolones and carbapenems) was restricted as a complement to the previously implemented measures for all wards in the facility. The outbreak was declared as controlled in the first week of August 2009, after eight weeks of continuous pre outbreak $C$. difficile incidence rate.

The control strategies were upheld as part of routine control procedures until 2010 to prevent further $C$. difficile nosocomial outbreaks. It was shown that the sustained presence of these strategies led to the maintenance of the usual incidence rate (Figure 1).

The overall mortality rate during the outbreak period was $11.0 \%(12 / 109)$ in cases and $6.2 \%(20 / 314)$ in controls. Higher mortality was noted in patients older than 65 years, and reached $18.0 \%(11 / 61)$ in cases compared to $10.4 \%(14 / 134)$ in controls.

\section{Factors associated with the outbreak}

Affected patients were predominantly 65 years or older in the affected group while the average age was younger in the control group. Differences in distribution according to sex were not found between groups $(p=0.82)$. A medical history of diabetes was more prevalent in the $C$. difficile group; however cancer was more frequent in the control group.

Antimicrobial therapy with cefotaxime, cephalothin, clarithromycin, levofloxacin and doxycycline and the use of proton- pump inhibitors were more common in the $C$. difficile positive group (Table 1).
Common symptoms associated with diarrhea were abdominal pain in $17.9 \%$ and vomiting in $10.4 \%$ of patients while uncommon symptoms included headache, weakness, and dyspnea.

An emergency condition was documented as the reason for admission in $59.6 \%$ of the cases and $57.9 \%$ of the controls. Affected patients were more likely to have been admitted to the emergency department for a period of observation than patients from the control group $(88.1 \%$ vs $65.3 \%)(p<0.01)$.

Adjusted associated risk factors for $C$. difficile infection were exposure to levofloxacin (OR: 9.3; 95\%CI: 2.1-40.2, $\mathrm{p}=0.003$ ), meropenem (OR: 4.9; 95\%CI: $1.0-22.9, \mathrm{p}=0.04$ ), cefotaxime (OR: 4.3; 95\%CI: 2.4-7.7, $\mathrm{p}<0.001$ ), clarithromycin (OR: 2.8; 95\% CI: 1.2-6.9, $\mathrm{p}=0.02$ ), ciprofloxacin (OR: 2.0; 95\% CI: $1.0-3.9, \mathrm{p}=0.04)$, and a history of diabetes mellitus (OR: 2.9; 95\%CI:1.5-5.8, p < 0.001) (Table 2).

\section{Discussion}

The results of the research analysis confirm that the implemented infection control measures were effective in controlling the $C$. difficile BI/NAP1 outbreak. It was also demonstrated that the outbreak was associated with the administration of broadspectrum antibiotics, principally carbapenems, quinolones and cephalosporins, as well as pre-existing medical conditions, in particular diabetes, a condition that was previously reported by Villalobos-Zúñiga in the outbreak description [12].

The main limitation of the study is that the $C$. difficile screening test used was not the most sensitive for $C$. difficile detection [18], thus there could have been a number of false negative cases. This was controlled by the restriction of enrollment in the control group of patients with no symptoms of diarrheal disease, to prevent classification bias.

The infection control measures described in this report follow those recommended by SHEA and IDSA [16] recommendations that have been adopted in other documented outbreaks [4], but due to features of disease transmission [9], the non-intensive nature of the strategies initially implemented and the overall magnitude of the outbreak, the control measures implemented here did not produce immediate results, though they demonstrated effectiveness. Control of the C. difficile BI/NAP1 outbreak has been described as challenging but possible through the combination of various strategies such as the use of personal protective equipment, environmental cleaning and antimicrobial restriction $[3,19]$. 
The association of the outbreak with antimicrobials such as carbapenems, fluoroquinolones, cephalosporin and clarithromycin is in agreement with the findings of other investigations of the BI/NAP1 strain $[1,2]$.

The restricted use of such antibiotics as a $C$. difficile outbreak control strategy are considered to be an effective intervention to reduce $C$. difficileassociated diarrheal infections [20,21], which was demonstrated in the Costa Rican outbreak as effective in achieving outbreak control.

The high mortality documented with $C$. difficile could be attributed, in part, to the superimposition of the BI/NAP1 strain over a non-hypervirulent strain as a result of selective antimicrobial pressure, similar to that suggested in Canadian outbreaks [7,22]. However, it is acknowledged that advanced age is a predisposing factor that was also likely a significant contributor to poorer outcomes [7].

In conclusion, the recommended infection control strategies adopted [16] based on the SHEA recommendations [18] demonstrated effectiveness in controlling the Costa Rican $C$. difficile BI/NAP1 outbreak and in maintaining the usual pre-outbreak $C$. difficile incidence rate. The SHEA, which is one leading organization in the United States in revising infection control strategies related with hospital infections, including $C$. difficile and it could be applicable in Latin American countries, to improve the control and preventive actions for nosocomial infections. Nonetheless, infection control systems must continue to be rigorously enforced and include improvements in early case detection to allow for timely implementation of intensive control measures to reduce $C$. difficile transmission.

The major factor associated with the $C$. difficile BI/NAP1 outbreak was the prescription of broadspectrum antibiotics, which has been documented in previous reports. The increasing use of broadspectrum antimicrobial drugs has resulted in a need to advocate for antimicrobial and a serious evaluation of the role of antimicrobial prescription as part of infection control surveillance systems.

Costa Rica's hyper virulent $C$. difficile outbreak should alert other Latin American hospitals of the emergence of this specific strain in our countries and its potential role in future diarrheal outbreaks.

\section{Acknowledgements}

Hospital personnel of Medical Records, Clinical Laboratory, Infection Control Committee and everyone who contributed with control actions during the outbreak.

Special gratitude to the Department of Pathology and Laboratory Medicine at Vancouver General Hospital in Canada and British Columbia Centre for Disease Control authorities, who provided technical recommendations to the investigation team during the outbreak.

Special gratitude to the Caja Costarricense de Seguro Social (CCSS) for their collaboration in the study. The study was conducted with the approval of the bioethics committee from the CCSS, and the data are property of this institution. For the investigation titled "Infection Control Practices and Associated Factors to hyper virulent Clostridium difficile strain Outbreak in Costa Rica", all authors report no conflicts of interest relevant to this article.

Financial Support: This study was funded by the Caja Costarricense de Seguro Social (CCSS).

\section{References}

1. Al-Tawfiq JA, Abed MS (2010) Clostridium difficileassociated disease among patients in Dhahran, Saudi Arabia. Travel Med Infect Dis 8: 373-376.

2. Sundram F, Guyot A, Carboo I, Green S, Lilaonitkul M, Scourfield A (2009) Clostridium difficile ribotypes 027 and 106: clinical outcomes and risk factors. J. Hosp. Infect 72 : $111-118$

3. O'Connor JR, Johnson S, Gerding DN (2009) Clostridium difficile infection caused by the epidemic BI/NAP1/027 strain. Gastroenterology 136: 1913-1924.

4. Weber DJ, Rutala WA, Miller MB, Huslage K, SickbertBennett E (2010) Role of hospital surfaces in the transmission of emerging health care-associated pathogens: norovirus, Clostridium difficile, and Acinetobacter species. Am J Infect Control 38 Suppl 1: 25-33.

5. Ananthakrishnan AN (2011) Clostridium difficile infection: epidemiology, risk factors and management. Nat Rev Gastroenterol Hepatol 8: 17-26.

6. Indra A, Huhulescu S, Fiedler A, Kernbichler S, Blaschitz M, Allerberger F (2009) Outbreak of Clostridium difficile 027 infection in Vienna, Austria 2008-2009. Euro Surveill 14: 1-2

7. Labbé AC, Poirier L, Maccannell D, Louie T, Savoie M, Béliveau C, Laverdière M, Pépin J (2008) Clostridium difficile infections in a Canadian tertiary care hospital before and during a regional epidemic associated with the BI/NAP1/027 strain. Antimicrob Agents Chemother 52: 3180-3187.

8. Perera AD, Akbari RP, Cowher MS, Read TE, McCormick JT, Medich DS, Celebrezze JP Jr, Beck SJ, Fischer PE, Caushaj PF (2010) Colectomy for fulminant Clostridium difficile colitis: predictors of mortality. Am Surg 76: 418421.

9. Viswanathan VK, Mallozzi MJ, Vedantam G (2010) Clostridium difficile infection: An overview of the disease and its pathogenesis, epidemiology and interventions. Gut Microbes 1: 234-242.

10. Balassiano IT, Dos Santos-Filho J, de Oliveira MP, Ramos MC, Japiassu AM, Dos Reis AM, Brazier JS, de Oliveira 
Ferreira E, Domingues RM (2010) An outbreak case of Clostridium difficile-associated diarrhea among elderly inpatients of an intensive care unit of a tertiary hospital in Rio de Janeiro, Brazil. Diagn Microbiol Infect Dis 68: 449-455.

11. Walker AS, Eyre DW, Wyllie DH, Dingle KE, Harding RM, O'Connor L, Griffiths D, Vaughan A, Finney J, Wilcox MH, Crook DW, Peto TE (2012) Characterisation of Clostridium difficile hospital ward-based transmission using extensive epidemiological data and molecular typing. PLoS Med 9:e1001172.

12. Villalobos-Zúñiga MA, Boza-Cordero R (2012) Caracterización epidemiológica, clínica y microbiológica del brote de diarrea asociado a Clostridium difficile, ocurrido en el Hospital San Juan de Dios, 2008-2009. Acta Médica Costarricense 54: 152-158.

13. Camacho-Ortiz A, Galindo-Fraga A, Rancel-Cordero A, Macías AE, Lamothe-Molina P, Ponce de León-Garduño A, Sifuentes-Osornio J (2009) Factors associated with Clostridium difficile disease in a tertiary-care medical institution in Mexico: a case-control study. Rev Invest Clin 61: 371-377.

14. Quesada-Gómez C, Rodríguez C, Gamboa-Coronado Mdel M, Rodríguez-Cavallini E, Du T, Mulvey MR, VillalobosZúñiga M, Boza-Cordero R (2010) Emergence of Clostridium difficile NAP1 in Latin America. J Clin Microbiol 48: 669670.

15. Edwardes M (2001) Sample size requirements for casecontrol study designs. BMC Med. Res Methodol 19: 1-5.

16. Cohen SH, Gerding DN, Johnson S, Kelly CP, Loo VG, McDonald LC,Pepin J, Wilcox MH (2010) Clinical practice guidelines for Clostridium difficile infection in adults: 2010 update by the society for healthcare epidemiology of America (SHEA) and the infectious diseases society of America (IDSA). Infect Control Hosp Epidemiol 31: 431-455.

17. Hacek DM, Ogle AM, Fisher A, Robicsek A, Peterson LR (2010) Significant impact of terminal room cleaning with bleach on reducing nosocomial Clostridium difficile. Am J Infect Control 38: 350-353.

18. Tenover FC, Novak-Weekley S, Woods CW, Peterson LR, Davis T, Schreckenberger P, Fang FC, Dascal A, Gerding DN, Nomura JH, Goering RV, Akerlund T, Weissfeld AS, Baron EJ, Wong E, Marlowe EM, Whitmore J, Persing DH (2010) Impact of strain type on detection of toxigenic Clostridium difficile: comparison of molecular diagnostic and enzyme immunoassay approaches. J. Clin. Microbiol 48: 3719-3724.

19. Horejsh D, Kampf G (2011) Efficacy of three surface disinfectants against spores of Clostridium difficile ribotype 027. Int J Hyg Environ Health 214: 172-174.

20. Al-Obaydi W, Smith CD, Foguet P (2010) Changing prophylactic antibiotic protocol for reducing Clostridium difficile-associated diarrhoeal infections. J Orthop Surg (Hong Kong) 18: 320-323.

21. Gulihar A, Nixon M, Jenkins D, Taylor GJ (2009) Clostridium difficile in hip fracture patients: prevention, treatment and associated mortality. Injury 40: 746-751.

22. Oake N, Taljaard M, van Walraven C, Wilson K, Roth V, Forster AJ (2010) The effect of hospital-acquired Clostridium difficile infection on in-hospital mortality. Arch Intern Med 170: 1804-1810.

\section{Corresponding author}

Roy A Wong-McClure

Epidemiology Office and Surveillance, Caja Costarricense de Seguro Social, Genaro Valverde Building, Second Avenue, San José, Costa Rica, Central America,

Telephone: 506-22553565, Fax: 506-22579052.

E-mail: rwong@ccss.sa.cr

Conflict of interests: No conflict of interests is declared. 